Farum

Sociológico

Forum Sociológico

Série II

23 | 2013

Número 23

\title{
Entre dons: itinerário de pesquisa sobre solidariedades familiares no desemprego
}

Isabel Marçano

\section{(2) OpenEdition}

\section{Journals}

\section{Edição electrónica}

URL: https://journals.openedition.org/sociologico/793

DOI: 10.4000/sociologico.793

ISSN: 2182-7427

Editora

CICS.NOVA - Centro Interdisciplinar de Ciências Sociais da Universidade Nova de Lisboa

\section{Edição impressa}

Data de publição: 1 novembro 2013

Paginação: $21-29$

ISSN: 0872-8380

\section{Refêrencia eletrónica}

Isabel Marçano, «Entre dons: itinerário de pesquisa sobre solidariedades familiares no desemprego», Forum Sociológico [Online], 23 | 2013, posto online no dia 01 janeiro 2014, consultado o 29 março 2022. URL: http://journals.openedition.org/sociologico/793 ; DOI: https://doi.org/10.4000/sociologico. 793

Este documento foi criado de forma automática no dia 29 março 2022.

(c) CICS.NOVA 


\title{
Entre dons: itinerário de pesquisa sobre solidariedades familiares no desemprego
}

\author{
Isabel Marçano
}

\section{Breves considerações teóricas}

\section{Desemprego}

1 O desemprego é, atualmente, um dos problemas incontornáveis, prementes e dramáticos, cuja compreensão se relaciona com a existência de uma organização social economicamente baseada no predomínio de relações salariais no modo de produção capitalista.

2 A disjunção entre tempo de trabalho destinado a rendimento e tempo de trabalho privado ou doméstico constitui uma das caraterísticas do trabalho assalariado. Trata-se de atividade na esfera pública e à qual é reconhecida utilidade traduzida em rendimento e posição social.

3 A composição do volume de desemprego é bastante diferenciada, acusando um desemprego a duas velocidades: desemprego de transição e desemprego de exclusão (Clavel, 2004). Se, no primeiro, o curto tempo de afastamento do mercado de trabalho não compromete possibilidades de reinserção, no segundo, ao prolongar-se, corporiza a precariedade crónica do desemprego de exclusão.

4 Portugal, em 2006, contava nos Centros de Emprego mais de 440000 desempregados, valor sobejamente aumentado desde então. 


\section{Proteção no desemprego, "sociedade-providência" e "familismo amoral"}

$\mathrm{Na}$ Europa, os Estados-Providência definiram o desemprego, o estatuto de desempregado, e desenharam "mediadores de compensação" (Gallie e Paugam, 2000), como proteções sociais aos desempregados para enfrentarem a privação de emprego. 0 regime de proteção no desemprego tem efeito decisivo na privação financeira. As coberturas estatais apresentam grande heterogeneidade na União Europeia (UE). 0 regime de proteção mais próximo da realidade dos países do Sul da Europa é o "subprotetor", onde é maior a probabilidade de os beneficiários se confrontarem com dificuldades financeiras graves ou viverem abaixo do limiar de pobreza com fortes possibilidades de o desemprego se prolongar. Em Portugal, em Agosto de 2009, apenas $46 \%$ dos desempregados inscritos nos Centros de Emprego (CE) recebiam subsídio de desemprego. Em 2011 a cobertura do subsídio de desemprego diminuiu (41,1 \% no 4.․․ trimestre), o que dá ideia do agravamento da fragilidade da cobertura da proteção social.

6 No caso da sociedade portuguesa, as lacunas de proteção abertas pelo regime "subprotetor" encontram-se compensadas pela ação de uma "sociedade-providência" (Santos, 1995) onde as redes de relações sociais substituem o Estado - pela reduzida "des-institucionalização" do modelo de família tradicional e pelos apoios familiares (Loison, 2002), apesar do enfraquecimento da "sociedade-providência" nas últimas décadas (Rodrigues, s. d.).

7 As trocas intergeracionais permanecem uma realidade. No Sul da Europa e em Portugal tende a predominar um padrão familiar em que os filhos saem tardiamente de casa. Além disso, a tradição parece combinar-se com dificuldades económicas e favorecer um modelo de residência familiar que, embora tendencialmente nuclear, evidencia alguma dependência extensiva com "institucionalização" do modelo de família tradicional e apoios entre familiares.

8 O conceito de "familismo amoral" articula as noções de sociedade, mercado e Estado e é caraterizado pela centralização na esfera privada com ganhos na família nuclear desligados do bem comum. O conceito tem validade para sociedades fortemente desigualitárias (Banfield, 1958; Elisa Reis,1995). Tal hipótese, que sugerimos válida para o contexto português do desemprego, é validada por M. Villaverde Cabral (2002) a propósito do campesinato pobre. É provável que os trabalhadores mais desfavorecidos e os desempregados atingidos por carência económica se limitem a apoios e iniciativas em circuito privado.

\section{Solidariedade, dom e troca}

9 A responsabilidade ou dependência mútua entre duas ou mais pessoas na família caraterizam a solidariedade familiar. Daí resulta a cooperação e estão presentes elementos de dádiva ou dom, independentemente da reciprocidade. Esta pode ser diferida.

10 Granovetter (1973) introduziu novos conceitos de rede e classificou os laços sociais existentes em fracos (weak ties), aqueles nos quais o investimento é menor ou nulo (e.g., indivíduos participantes de um grupo ou associação) e fortes (strong ties), nos quais os 
indivíduos empenham mais tempo, intensidade emocional e trocas (e.g., círculo familiar e de amigos).

11 O movimento de dádivas e retribuições foi abordado por Mauss (1923-1924) como fenómeno complexo e paradoxal das sociedades ditas primitivas ou arcaicas. Em contrapartida, Lévi-Strauss (1974 e 1978) assinalou a realidade estrutural da troca. No caso do desemprego, é legítimo perguntar se ocorrem trocas e solidariedades, como ocorrem e como são identificadas pelos envolvidos.

Dar, receber e retribuir é próprio das relações sociais. No contexto familiar podem trocar-se bens de natureza diversa. $O$ reconhecimento de necessidades familiares e a disponibilidade para ajudar são duas condições básicas para concretização de dádivas sob formas diversas. No ciclo de vida familiar, várias lógicas se entretecem: "lógica da necessidade", "lógica da reciprocidade" e "lógica da complementaridade" (AttiasDonfut, 1998) por referência ao dar, receber e retribuir de Mauss. As trocas ocorrem segundo relações de doação e reciprocidade (Razeto in Tiriba, 2004). ${ }^{1}$

13 Entre familiares os dons assumem, frequentemente, a forma de ajuda ou apoio. 0 apoio social tem sido considerado de diferentes formas (Cobb, 1976; Thoits, 1982; Warr, Jackson e Banks, 1982). Distinguimos dois tipos de apoio social (instrumental ou material e socioemocional) que conservam os atributos de dádiva ou dom, são dinâmicos e mutuamente permeáveis na circulação de bens, serviços e afetos. Além disso, Casal (2005) propõe que a base de regulação da dádiva entre familiares não se baseia na norma da reciprocidade ${ }^{2}$ mas no princípio da dívida ${ }^{3}$. Essa dívida tende a ser positiva, pois gera reconhecimento e sentimento de agrado pela dádiva recebida, não exigindo retribuição e quitação. Aqui é usada a noção de relações de reciprocidade no sentido do fluxo bilateral ou unilateral, sem acordo do intercâmbio nem proximidade temporal, conforme Razeto, in Tiriba (2004).

\section{Metodologia}

Com o objetivo de identificar se ocorrem trocas e solidariedades, como ocorrem e como são identificadas pelos envolvidos, foram inquiridos 300 desempregados $^{4} \mathrm{e}$ analisadas questões colocadas num inquérito por questionário mais vasto. $O$ inquérito decorreu entre dezembro de 2005 e janeiro de 2006, complementado com a realização de sessenta entrevistas até julho de 2006.

\section{Resultados empíricos}

\section{Inquérito por questionário}

\section{Proteção social e situação financeira}

15 A situação financeira dos desempregados permite esclarecer os níveis de proteção social dos inquiridos para enfrentar a privação de emprego. Como o tipo de regime de proteção no desemprego tem importância decisiva na privação financeira e esta, por sua vez, poderá implicar maior envolvimento da rede familiar e social nos apoios no desemprego, este foi um ponto prévio à análise das trocas e solidariedades no desemprego. 


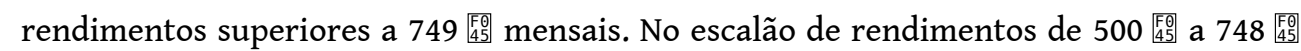
mês enquadram-se $23,2 \%$. O destaque incide, no entanto, sobre inquiridos cujos agregados dispõem de rendimento mensal inferior a 499 雬 mês, sugerindo condições de pobreza e exclusão social para $17,6 \%$, com realce para $2 \%$ com rendimento igual ou inferior a 150 踇 mês.

Complementando estes dados com informação relativa à capacidade de poupança, verifica-se que a sustentabilidade económica da generalidade dos agregados se carateriza de precária (37,2\% gastam todo o dinheiro disponível, $40,1 \%$ têm de prescindir de bens necessários e $6,4 \%$ chegam a endividar-se). Somente $16,3 \%$ dos agregados dão sinais de estabilidade económica com capacidade de poupança.

Sobre a proteção social, nota-se que a maioria dos inquiridos $(86,2 \%)$ beneficia de subsídio de desemprego. Entre os restantes ( $\mathrm{N}=38$ ), identifica-se assinalável proporção de situações de precariedade, dado que, ocorrendo o desemprego em muitos casos por motivos não imputáveis aos inquiridos, estes não recebem subsídio de desemprego.

Quanto ao escalão de subsídio de desemprego e pensão, aparece uma concentração em torno dos limites inferior e superior do salário mínimo nacional (37,2 \% com subsídio

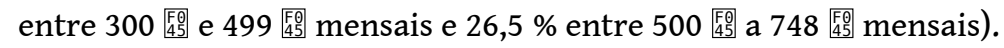

Há que realçar ainda a percentagem de inquiridos com subsídios inferiores a 299 mensais (13\%), situados assim em limiar de pobreza e de exclusão, considerando, nomeadamente, $2,3 \%$ no escalão mínimo de 0 a 150 緊 mensais. Por contraste, $23 \%$ dos inquiridos auferem prestação mais generosa (valor superior a 749 堅).

21 Tais dados assumem especial relevância quando se verifica que cerca de $2 / 3$ dos inquiridos têm como principal fonte de sobrevivência o subsídio. Destaca-se ainda a assunção da família como importante estrutura de sustento e apoio para cerca de $1 / 3$ dos inquiridos, onde cônjuge/companheiro(a) assim como pais assumem particular destaque.

22 A propósito ainda dos aspetos económicos, a grande maioria dos inquiridos (95\%) concorda em ter ficado com menos dinheiro após o desemprego.

\section{Ecologia habitacional e familiar}

23 A ecologia familiar apresenta caraterísticas favoráveis à ocorrência de trocas, como se verá.

24 Mais de metade dos inquiridos reside em casa própria. Seguem-se situações de residência em casa alugada e em casa dos pais, em percentagens muito próximas. Menor percentagem reside em quarto alugado.

25 Sendo a residência em casa dos pais fator importante da comunidade de recursos e sustentabilidade económica perante o desemprego, considerou-se relevante apresentar uma caraterização da situação familiar dos inquiridos em tais condições (N=57). Cerca $\mathrm{de}^{2} / 3$ dos residentes em casa dos pais são solteiros; os restantes casados/ /união de facto (19,3\%) ou divorciados/separados de facto (15,8 \%).

Os inquiridos não se encontram em circunstância residencial de isolamento, sendo que mais de metade vive com 2 ou 3 pessoas, $26 \%$ com $^{4}$ ou mais pessoas e apenas $18,1 \%$ com 1 pessoa. 

próprio agregado familiar (mulher/marido/companheiro/a e filhos). Cerca de $20 \%$ constituem família nuclear confinada a cônjuges e $5 \%$ apenas com filhos. $O$ agregado familiar de $20 \%$ dos indivíduos é família alargada a três gerações (pais/irmãos/avós). Note-se que, em cerca de $1 / 4$ dos agregados domésticos, coexistem mais pessoas à procura de emprego, fator que certamente contribui para a fragilização de autossustentação e equilíbrio. O facto de $25 \%$ dos cônjuges/companheiros(as) dos inquiridos não trabalhar é digno de nota, pois poderá constituir indicador de precariedade, insegurança e/ou dificuldade de sustentabilidade económica de $1 / 4$ das famílias. Também o contacto com pessoas desempregadas é comum na restante esfera social dos inquiridos (78,2\% têm outros familiares ou amigos desempregados).

Uma análise da proximidade geográfica entre familiares mais diretos permite afirmar que, no geral, existe grande proximidade: quase $30 \%$ residem na mesma freguesia e cerca de $24 \%$ no mesmo concelho.

\section{Sociabilidade familiar}

30 Ao analisar a visita entre familiares, conclui-se que a periodicidade diária ou semanal é a prática mais comum $(56,1 \%)$, embora $37 \%$ expressem visitas pontuais ou a sua inexistência. Uma minoria $(6,8 \%)$ expressa uma prática mensal de visitas. A proximidade geográfica e os contactos sociais entre os familiares mais chegados configuram proteção psicológica e integração social face ao desemprego.

\section{Solidariedade e trocas familiares}

31 Tendo como fundo os dados anteriores, analisaram-se solidariedades familiares e trocas entre indivíduos em situação de desemprego.

Relativamente à ajuda de familiares, a maioria (70 \%) afirma não receber qualquer tipo de ajuda, mas ainda assim é expressiva a percentagem dos que dela beneficiam (30\%).

Quanto à ajuda, predomina a financeira (53,4\%). No entanto, a ajuda no alojamento é também identificada por bastantes inquiridos (21,9\%). Num terceiro nível e com expressão análoga surgem duas ajudas: cuidar dos filhos (12,3 \%) e alimentação (11 \%).

34 Solidariedades e trocas familiares foram analisadas em entrevistas complementares ao inquérito, sendo notório que ocupação do tempo, trocas, solidariedades e ajudas interagem no contexto do desemprego.

\section{Entrevistas ${ }^{5}$}

Da investigação emerge que no desemprego se perdem variáveis organizacionais de gestão do tempo, embora apareçam outros marcadores, como as obrigações para com o Estado, ou se reforcem deveres e trocas com a família.

36 A maioria dos homens opta por criar rotinas que permitem sair de casa. Não só, para alguns, porque a casa é o espaço tradicional feminino, mas por motivos de isolamento e de busca do convívio social e de emprego. As mulheres, mesmo as mais jovens, tendem a permanecer mais tempo em casa e a manter um sentido social pelo cuidar da casa, filhos, netos ou pais idosos. 
37 As mães têm em comum o facto de pautarem a vida pelas necessidades da prole. 0 material das entrevistas evidencia padrões temporais e de trocas comuns às vidas de mulheres, sobretudo operárias, mas com variação em função da idade.

Muitas mulheres, influenciadas pela tradição ou limitadas pela falta de recursos financeiros ou por carência de estruturas na sua área de residência, assumem o cuidado de filhos e pais. Assim, evitam também um acréscimo das despesas. No global, as mulheres comungam da realização de atividades no tempo social familiar com a execução de tarefas diversas. A descrição destas atividades é assinalada pelas mulheres das classes operárias e burocráticas como ações que preenchem os dias; não são porém destacadas pelas mulheres de profissões técnicas, intelectuais e científicas.

A partir dos cinquenta anos surgem mais casos de desempregadas que assumem outro papel de apoio familiar ao tomar conta de mães ou pais idosos, situação relevante na economia doméstica, quer os pais partilhem ou não do mesmo agregado doméstico.

Em geral, são poucos os homens que dedicam tempo a atividades domésticas, embora passem mais tempo em casa e dêem mais apoio a filhos ou netos. De facto, e comparativamente às mulheres, os homens estão menos presentes no tempo familiar: menos centrados e ocupados em casa e muito menos em atividades domésticas, ainda que alguns afirmem "dar uma ajuda" ou cozinhar. Para muitos, se a casa é objeto de trabalho, é-o enquanto estrutura a melhorar (pinturas, pequenos arranjos ou grandes obras), sublinhando alguns relatos o contributo deste trabalho para a economia familiar.

Vejam-se alguns exemplos de quem recebe ajuda.

42 A., com 22 anos, tem uma filha de vinte e quatro meses. Operária fabril, apenas concluiu o 6. ${ }^{\circ}$ ano de escolaridade. Desempregada há dois anos, não aufere subsídio. 0 marido trabalha em oficina e recebe o salário mínimo nacional. Os pais vivem na mesma freguesia e as mulheres e criança dos dois grupos domésticos encontram-se várias vezes por semana. Os avós dão apoio à jovem família: cuidam da neta quando necessário, oferecem alimentos da horta, preparam refeições, sendo as trocas sobretudo dinamizadas no feminino.

B., solteira sem filhos, tem 25 anos e o 12. ano de escolaridade. Vive com os pais e está desempregada há três meses. Tem alguma experiência como caixeira de loja, não aufere subsídio e conta com o apoio financeiro e de alojamento por parte dos pais. É um dos casos raros que se dedica a algum trabalho de voluntariado (com idosos), para além da procura de emprego.

44 C. é mulher de 27 anos, engenheira industrial, casada e sem filhos. 0 marido é bancário. Com experiência de trabalho na área comercial, deseja um emprego na sua área profissional. Desempregada há dois meses, tem subsídio que durará por dez meses e recebe apoio do marido. Cuida da casa, prepara refeições e procura emprego.

o subsídio não é muito mas é importante para as minhas despesas. Assim não fico completamente dependente do marido. $O$ pior é se não consigo emprego antes de acabar. Os meus pais vivem noutro concelho e o meu pai também está desempregado. Encontramo-nos aí uma vez por mês e sei que só não ajudam se não puderem. Eu não lhes peço nada porque tenho o meu marido e o meu pai também ficou sem emprego.

Como se viu no caso de A., para muitas mulheres a dedicação aos filhos, sobretudo em tenra idade, é substituto de atividade profissional e facilita a adaptação ao tempo no desemprego. Tal refere D., mulher com 28 anos, casada e com o 7. ano unificado, 
operária durante seis anos; desempregada com subsídio de desemprego há dois anos. $\mathrm{O}$ nascimento de um filho marca grande mudança no ciclo de vida doméstica, a que se veio juntar outra mudança, o desemprego. Visita os pais com muita frequência e recebe apoio no cuidar do filho.

E., 32 anos e separada com uma criança a cargo, ficou desempregada pela terceira vez. Divide o tempo entre cuidar do filho e procurar emprego, nomeadamente com deslocações semanais ao Centro de Emprego. Expressa dificuldades de sobrevivência e restrições financeiras devido ao baixo valor do subsídio. Equaciona a hipótese de regressar a casa dos pais com o filho, caso o desemprego persista. Entretanto, predominam as trocas afetivas entre avó, mãe e neto.

47 Todas as mulheres entre 30 e 34 anos passaram a orientar o tempo no desemprego em função dos filhos, da confeção de refeições e das atividades domésticas, mesmo se procuram emprego. Esta circunstância também é válida para mulheres entre os 35 e os 45 anos (independentemente do nível de instrução), à exceção de duas que não têm filhos.

48 Com 40 anos de idade, F. tem apenas a $4 .^{\mathrm{a}}$ classe e está desempregada há seis meses. Ficou desempregada depois de ter trabalhado num lar de idosos durante oito anos. Continuará a receber subsídio de desemprego durante dois anos. Mãe solteira, viveu maritalmente com o pai dos dois filhos, de quem está separada há dois anos mas que a apoia na renda de casa. Toma medicamentos para a depressão, não tem amigos nem família próxima. Todavia, as relações de proximidade são geradoras de apoios solidários e, assim, conta com apoio de uma vizinha a quem ajuda na horta e a cuidar dos animais, recebendo em troca produtos hortícolas. Também uma ex-patroa a ajuda com roupas e alimentos.

Quanto às visitas a familiares, no total $59 \%$ das mulheres até aos 45 anos referem visitar diariamente a família, sobretudo as mães que também se encontram em casa. De facto, as visitas a familiares, especialmente às mães, estão muito presentes no mundo feminino. As mulheres são as grandes dinamizadoras das sociabilidades e das trocas na família em sentido ascendente e descendente.

50 Considere-se G. (37 anos, 9. ano de escolaridade, casada), desempregada do comércio desde que engravidou e sem subsídio. Visita diariamente a mãe acompanhada do seu bebé e conta com o seu apoio. Cuidar do bebé, tarefas domésticas, sociabilidade e apoio familiar ao sobrinho são aspetos centrais na gestão do tempo.

51 H. é outra mulher casada, 39 anos, sem filhos, frequência universitária e técnica administra-

tiva. Visita diariamente os pais, com quem almoça. Procura emprego no jornal e, enquanto não consegue, ocupa parte do tempo em aprendizagens ligadas às artes.

52 A grande maioria das mulheres de todos os grupos etários e de escolaridade indica maior dedicação à família e filhos após o desemprego.

53 A procura activa de emprego e o interesse em investir num negócio são assinalados por I. (41 anos, mãe solteira), com uma filha de vinte anos. I. tem o curso de técnica de turismo e a frequência do terceiro ano da licenciatura em Economia. Natural de Angola, de onde viajou para Portugal com a família após o 25 de Abril de 1974, trabalhou como técnica de turismo durante dez anos e está desempregada há sete meses, com direito a subsídio durante dois anos. Não esgota o tempo em atividades domésticas. Almoçar em casa da mãe é mais uma regularidade que volta a aparecer. Dá à mãe, filha e sobrinhos o 
apoio afetivo e para resolução de pequenos problemas, nomeadamente nas atividades escolares, pagamento de contas, ida ao médico.

J. (45 anos, produtora cinematográfica executiva, sem subsídio), separada do marido (jornalista e também ele desempregado), tem 4 filhas em idade escolar e pertence a uma família socialmente diferenciada. Esgotado o tempo de subsídio, vive dificuldades económicas sérias e pretende solicitar o RSI. J. ocupa muito tempo a procurar emprego e assinala o apoio familiar recebido da mãe.

Vivo com o apoio da minha mãe. Se a minha mãe não me ajudasse eu estaria a viver debaixo da ponte e a passar fome com as minhas filhas. A minha mãe tem 81 anos e vem todos os dias do castelo até à minha casa para ver se está tudo bem. Ajuda-me muito em termos financeiros. Ela agora foi passar uns tempos à quinta a Torres Novas mas liga todos os dias para saber se está tudo bem.

L. (39 anos, 12.. ano de escolaridade, casado, uma filha, desempregado há cinco meses) assinala a importância do apoio familiar de ambos os lados da família reforçada pela proximidade de residência e ampliada pelo batismo.

Posso contar com a ajuda dos meus pais e dos meus sogros e os padrinhos também dão uma ajuda para o bebé. Vivemos perto dos meus sogros e há sempre alguma ajuda a tomar conta da menina e na nossa alimentação, muitas vezes vamos comer à casa dos meus sogros ou à dos meus pais, eles sabem que eu estou desempregado $\mathrm{e}$ preocupam-se.

J. C. (28 anos, desempregado há 3 meses, sem subsídio) vive em união de facto com a companheira, 25 anos, também desempregada, e a filha em casa alugada. O casal conta com apoio financeiro dos pais de ambos e deste modo conseguem sobreviver: "Se não fosse a família não sei como seria, eu estou desempregado e ela também. Temos ajudas dos meus pais que vivem perto e dos pais dela que estão na Suíça. Enviam dinheiro todos os meses."

5 M. (32 anos de idade, 8. ano de escolaridade, casado com três filhas), tem a mulher desempregada e vivem em casa alugada. Nos últimos meses o casal tem sobrevivido e pagado as despesas da casa com o apoio da mãe de M., que, todavia, não pode continuar a suportar as despesas, pelo que a solução é o realojamento dentro de dias em família alargada em casa da mãe. Receberão assim apoio em alojamento, alimentação e no cuidar das crianças.

A dádiva bilateral não é rara. Acontece com A. R. (35 anos, solteiro, sem filhos, desempregado há 10 anos), que recebe alojamento em casa da mãe, a quem presta cuidados. Esta situação é limitativa de acesso ao mercado de emprego, ocorrência mais vulgar em mulheres acima dos 55 anos de idade a cuidar de pais idosos.

Sandra, 31 anos, reside com o companheiro desempregado e dois filhos. Está desempregada há dois anos, sem subsídio e aufere RSI. Este caso constitui outro bom exemplo do papel das redes familiares como suporte social e apoio socioeconómico.

Se não fosse a ajuda dos meus pais não sei como seria. Já tínhamos entregado a casa. Mas a minha mãe ajuda-me muito e a minha avó que já morreu também me dava muito. Quando a minha avó morreu a minha mãe vendeu uma casa na terra e do que recebeu deu logo 500 euros a cada filha. Está sempre a ajudar. Custa-me pedir mas ainda agora vai ter que ser pois chegou uma carta de corte de luz. A minha mãe não dá dinheiro, por exemplo para um café; se queremos, fazemos em casa, mas não quer que nos falte nada. Vamos ao hipermercado e ela paga as despesas das compras do mês, paga a prestação da casa, água, gás e luz. 

(nive só num apartamento que comprou há anos com empréstimo bancário mas que, face ao desemprego, só consegue pagar com ajuda da irmã. Contudo, o desemprego de um elemento da família e a necessidade de receber apoio financeiro pode provocar desequilíbrios e até conflitos familiares: "A minha irmã empresta-me dinheiro, que é como quem diz dá, porque se calhar não tenho hipótese de lho pagar. Mas já teve problemas com o marido. Para me ajudar a mim tem problemas com o marido. Se as coisas se complicarem talvez tenha que entregar a casa ao banco."

É evidente que a partilha de alojamento ou a proximidade física de agregados domésticos facilita sociabilidades e trocas nas famílias de desempregados. Laços afetivos, disponibilidade financeira e de tempo são outros fatores cruciais na dinamização ascendente e descendente de solidariedades. Como se viu, um padrão diário relevante são as visitas entre familiares, particularmente entre mães e filhas, fenómeno que proporciona solidariedades e trocas familiares. A partir dos 48 anos de idade surgem, com alguma frequência, relatos de homens e, sobretudo, de mulheres no apoio a netos. Além disso, é notório que o apoio das filhas às mães idosas, nomeadamente no cuidar das mesmas, e o zelo dos netos se acentua nas mulheres maiores de 55 anos. 


\section{Reflexões finais}

pais. Foi nítida a emergência de um claro padrão feminino a partir dos 55 anos, em que mais mulheres desempregadas assumem o papel de apoio familiar (cuidar de pais e netos), situação relevante na economia doméstica. Em geral e de forma evidente, são poucos os homens que dedicam tempo a atividades domésticas, embora passem mais tempo em casa e deem mais apoio à família. É evidente a dinâmica da dádiva entre familiares. Pode afirmar-se que se conta, primeiro que tudo, com a família. Muitos dos desempregados representam apoio para a família com importância nas trocas descendentes e ascendentes.

78 Em geral, as trocas surgem a partir dos afetos, como ajuda doméstica e financeira, cuidar de crianças e assistência na doença. Cuidar de pais é reciprocidade afetiva e instrumental diferida, ainda presente em filhas educadas num contexto tradicional. As 
que não conseguem regressar ao mercado de trabalho canalizam muito do seu tempo para trocas intergeracionais e constituem apoio familiar básico inscrito numa linha de dom e contra-dom matrilateral que envolve avós, filhas e netas.

É sobretudo no sentido descendente que ocorrem as transmissões económicas de pais para filhos jovens ou de avós para netos. A situação varia quando os pais já idosos, em lares ou em casa das filhas, necessitam de apoio financeiro e de cuidado, apesar de as filhas se encontrarem desempregadas. No caso de desemprego de pais mais idosos é frequente estes, sobretudo mulheres, cuidarem de netos e apoiarem os filhos nas refeições. Quando a componente feminina da família está desempregada, ocorre um reforço da atividade doméstica, mas as ações no contexto familiar também são reforçadas ao nível da dádiva descendente e ascendente: refeições para filhos já casados ou que vão almoçar a casa, cuidar de netos, visitar pais idosos e cuidar de pais e sogros co-residentes.

Embora menos frequentes e menos intensos, os dados indicam que parte dos homens desempregados se envolvem também na dádiva familiar (transportes; refeições; assistência na atividade escolar; apoio na construção de residência própria para filhos; assistência na escola dos netos; muito raramente, cuidado com mães idosas coresidentes).

81 Assim, o apoio no âmbito do dom e trocas nas famílias e redes sociais é mecanismo microssocial compensatório com importância relevante no desemprego. Considerando a proposta de Granovetter (1984), é notória a pujança dos laços fortes (círculo familiar) no desemprego com dispêndio de tempo, intensidade emocional e trocas num círculo restrito. Os bens trocados são de natureza diversa e mais facilmente referenciáveis pelos indivíduos quando se trata de rituais simbólicos ou de bens monetários.

Como se viu, necessidade, reciprocidade e complementaridade são lógicas que se abraçam nas trocas familiares sob a forma de ajuda ou apoio. Porém, no contexto familiar, a reciprocidade, em termos materiais, não está necessariamente presente entre pais e filhos. Entre familiares, o fluxo bilateral ou unilateral da dádiva, sem ajuste de permuta nem proximidade temporal, pode assumir formas de apoio variadas instrumental ou material (ajuda económica, conselho, informação, ajuda nas responsabilidades do trabalho e da família) e socioemocional (afeto, simpatia, aceitação e estima).

83 Os nossos dados vão ao encontro das conclusões de Straw e Elliot (1986), que consideram também as visitas e solidariedades entre mães e filhas um facto proeminente entre comunidades operárias da Escócia. Mães e filhas permanecem durante a maior parte da vida bastante próximas e recorrem menos ao apoio formal das instituições. O dia-a-dia de parte de muitas mulheres desempregadas não se confina aos lugares onde vivem, mas divide-se entre a sua casa e a casa das mães, onde passam parte regular do tempo, tal como Young e Willmott (1965) concluíram para comunidades operárias em Inglaterra.

Em suma, as solidariedades familiares desempenham um papel fundamental no desemprego como alternativa ou complemento à proteção social do Estado. A "sociedade-providência" revela-se bastante ativa no contexto do desemprego com redes sociais que substituem o Estado. Quando o modelo tradicional e os apoios familiares falham, é todo um risco de exclusão social que emerge. Dom, trocas e solidariedades são dinâmica relevante na economia e reprodução familiar dos desempregados. No contexto do desemprego, é clara a centralização na esfera privada 
potenciadora de ganhos na família nuclear. Atingidos por carência económica, são muito poucos os que se ligam à realização do bem comum por via da participação em movimentos associativos e de voluntariado, por exemplo. O "familismo amoral" tem, pois, na sociedade portuguesa e no desemprego, um sentido positivo correspondente a um ethos cultural de populações carenciadas em recursos materiais e simbólicos para responder a necessidades práticas de sobrevivência e reprodução familiar e social num circuito privado restrito à família e, por vezes, à cooperação com vizinhos.

Os dados sobre a pobreza em Portugal permitem concluir que os desempregados fazem parte das categorias com maior risco de pobreza, sobretudo quando não há direito ao subsídio de desemprego. Com o agravamento da crise económica desde 2008, a subida geral do desemprego e alastramento nas famílias, a par de menores apoios financeiros aos desempregados, é provável que a sobrevivência se venha agravando e que a "sociedade-providência", mantendo-se ativa em trocas e solidariedades, enfraqueça na sua capacidade de apoio.

\section{BIBLIOGRAFIA}

ATTIAS-DONFUT, C. (1998), La dynamique de l'entraide intergénérationelle, 1ères Rencontres Sauvy, INED.

BANFIELD, E. C. (1958), The Moral Basis of a Backward Society, Nova Iorque, The Free Press.

CABRAL, M. V. (2002), Despotismo do Estado e Sociedade Civil Real em Portugal: Distância ao poder, comunicação política e familismo amoral, Instituto de Ciências Sociais, Universidade de Lisboa.

CALEIRAS, J. (2011), Para Além dos Números - As Consequências Pessoais do Desemprego (Trajectórias de Empobrecimento, Experiências e Políticas), Tese (doutoramento), Coimbra, Faculdade de Economia da Universidade de Coimbra.

CASAL, A. Y. (2005), Entre a Dádiva e a Mercadoria. Ensaio de Antropologia Económica, Lisboa, edição do autor.

CLAVEL, G. (2004), Sociedade da Exclusão: Compreendê-la para Sair Dela, Porto, Porto Editora.

COBB, S. (1976), "Social support as a moderator of life stress", in Psychosomatic Medicine, 39 (5): 300-313.

FREYSSINET, J. (1991), Le Chômage, Paris, La Découverte, Collection Repères.

GALLIE, D. e S. Paugam (orgs.) (2000), Welfare Regimes and the Experience of Unemployment in Europe, Oxford University Press, Oxford.

GRANOVETTER, M. (1984), "Small is bountiful: labor markets and establishment size", in American Sociological Review, 49: 323-334.

LÉVI-STRAUSS, C. (1974), "Introdução à obra de Marcel Mauss" in M. Mauss, Sociologia e Antropologia, São Paulo, EPU/Edusp.

LÉVI-STRAUSS, C. (1978), Antropologia Estrutural, Rio de Janeiro, Tempo Brasileiro. 
LOISON, L. (2002), L’Expérience Vécue du Chômage au Portugal, tese (doutoramento), 2 vols., não publicada, Biblioteca do ISCTE.

MATOS, J. N., N. Domingos e R. Kumar (orgs.) (2012), Precários em Portugal, entre a fábrica e o call center, s. 1., Edições Le Monde Diplomatique.

MAUSS, M. (1923-1924), “Essai sur le don. Forme et raison de l'échange dans les sociétés archaïques”, in L'Année Sociologique, consultado em http://www.uqac.uquebec.ca/zone30/ Classiques_des_sciences_sociales/index.html

PEREIRA, V. (org.) (2012), Ao Cair do Pano. Sobre a formação da vida quotidiana num contexto (des)industrializado do Vale do Ave, Porto, Edições Afrontamento.

REIS, E. P. (1995), "Desigualdades e solidariedade: uma releitura do familismo amoral de Banfield" in Revista Brasileira de Ciências Sociais, 29: 35-58.

RODRIGUES, E. V. (s. d.), "Estado-providência e os processos de exclusão social: considerações teóricas e estatísticas em torno do caso português" in http:// ler.letras.up.pt/uploads/ficheiros/ 1477.pdf

SANTOS, B. S. (1994), "Sociedade-providência ou autoritarismo social?" in Revista Crítica de Ciências Sociais, 42, pp. I-VIII.

STRAW, P. e B. Elliot (1986), "Hidden Rhythms: Hidden Powers? Women and Time in WorkingClass Culture", in Life Stories/Récits de Vie, 2, pp. 34-47.

TIRIBA, L. (2004), "Ciência económica e saber popular: reivindicar o «popular» na economia e na educação", in L. Tiriba e I. Picanço (orgs.), Trabalhos e Educação: Arquitetos, Abelhas e outros Tecelões da Economia Popular Solidária, São Paulo, Ideias e Letras, pp. 75-102.

THOITS, P. A. (1982), “Conceptual, methodological and theoretical problems in studying support as a buffer against life stress", in Journal of Health and Social Behaviour, 23: 145-159.

WARR, P. B., P. Jackson, e M. Banks, (1982), "Duration of unemployment and psychological wellbeing in young men and women", in Current Psychological Research, 2: 207-214.

YOUNG, M. e P. Willmott (1965), Family and Kinship in East London, Londres, Routledge and Kegan Paul.

\section{NOTAS}

1. Relações de doação: quando um dos sujeitos se assume como doador e outro como beneficiário, o que não implica um fluxo correspondente no sentido inverso; relações de reciprocidade: quando os bens fluem bilateralmente, sem acordo do intercâmbio.

2. $O$ apoio dos pais aos filhos não se baseia na expetativa de retribuição.

3. Existem dois tipos de dívida: a dívida económica ou dívida negativa; a dívida positiva, quando existe um reconhecimento pela dádiva recebida.

4. 150 homens e 150 mulheres com idades compreendidas entre 16 e 60 anos e idade média de 40 anos. Os escalões etários distribuem-se de forma relativamente equitativa. 0 mesmo não acontece com o nível de instrução, onde se verifica uma diferença percentual entre níveis mais básicos (1.ำ 2. e 3. ciclos) e mais avançados (secundário e superior), sendo que a maioria dos desempregados aparece entre os primeiros. A generalidade é de nacionalidade portuguesa (cerca de $97 \%$ ). Os restantes vêm predominantemente de países de língua oficial portuguesa. A quase totalidade dos inquiridos (96\%) já teve emprego remunerado. A situação mais frequente corresponde a desemprego de média duração (3/4 entre 6 meses e 1 ano); 23,5\% a desemprego há menos de 6 
meses; $20 \%$ a desemprego de longa duração, com maior presença entre 1 e 2 anos. $40 \%$ dos inquiridos repete a situação de desemprego.

5. Realizaram-se 60 entrevistas a desempregados ( 30 mulheres e 30 homens entre 18 e 60 anos, escolaridade entre $1 .^{\circ}$ ciclo e licenciatura ou mais e diversos tempos no desemprego).

\title{
RESUMOS
}

Apresenta-se aqui uma reflexão sobre solidariedades familiares no desemprego em Portugal. Partindo do princípio de que, na sociedade portuguesa, há espaço para troca e dádiva, estudámos as suas manifestações no desemprego a partir de questões colocadas em inquérito mais vasto sobre vivências no desemprego de 300 desempregados na área da Grande Lisboa e 60 entrevistas. O inquérito decorreu entre dezembro de 2005 e janeiro de 2006. O desemprego gera privação de recursos materiais e disponibilidade de tempo. Este duplo aspeto proporciona reforço de apoio e trocas familiares. As solidariedades familiares desempenham papel fundamental como alternativa ou complemento à proteção social do Estado. No contexto do desemprego é clara a centralização na esfera privada potenciadora de ganhos na família nuclear, com destaque para as solidariedades femininas.

This article presents the preliminary outcome of family solidarities in unemployment in Portugal. Assuming that in the Portuguese society there is place for sharing and giving, we explored their manifestations on unemployment using some questions of a survey about the experience of unemployment of 300 unemployed in the Greater Lisbon area and 60 interviews. The inquiry was carried out between December 2005 and January 2006. Unemployment causes deprivation of material resources and time availability. This double unemployment contingency brings the reinforcement of family support and sharing. The family solidarity plays a key role as an alternative or complement to the social protection of the State. In the context of unemployment it is clear the centering on privacy-enhancing gains in the nuclear family, with emphasis on female solidarity.

\section{ÍNDICE}

Palavras-chave: desemprego, "sociedade-providência", "familismo amoral", dom, solidariedade Keywords: unemployment, "welfare-society”, “amoral familism”, gift, solidarity

\author{
AUTOR \\ ISABEL MARÇANO \\ Investigadora, Doutorada em Sociologia. Mestre em Antropologia Social e Cultural e Sociologia da \\ Cultura (FCSH/ UNL) (marcano.isabel@gmail.com)
}

